九州大学学術情報リポジトリ

Kyushu University Institutional Repository

\title{
A Study on Labor Force Reduction and Fruit Quality with the Use of Substances Showing Thinning Effect in 'Fuji' and 'Arisu' Apple Varieties
}

SON, Tae-Kwon

Department of Farm Management, College of Agriculture and Life Sciences, Kyungpook National University

OZAKI, Yukio

LEE, Kyeong-Yeol l

School of Applied Biosciences, College of Agriculture and Life Sciences, Kyungpook National University

https://doi.org/10.5109/4103701

出版情報: 九州大学大学院農学研究院紀要. 65 (2)，pp.257-261，2020-09. Faculty of Agriculture， Kyushu University

バージョン :

権利関係 : 


\title{
A Study on Labor Force Reduction and Fruit Quality with the Use of Substances Showing Thinning Effect in 'Fuji' and 'Arisu' Apple Varieties
}

\author{
Tae-Kwon SON ${ }^{1}$, Yukio OZAKI and Kyeong-Yeoll LEE ${ }^{2,3 *}$ \\ Laboratory of Horticultural Science, Division of Agrobiological Sciences, Department of Bioresource Sciences, \\ Faculty of Agriculture, Kyushu University, Fukuoka 819-0395, Japan \\ (Received May 18, 2020 and accepted May 27, 2020)
}

\begin{abstract}
Thinning is a common practice in apple production. Many thinning agents have been used to thin apples. The effectiveness of the agents depends on the apple variety and other factors such as orchard conditions or environmental ones. 'Fuji' is one of the apple varieties that is difficult to thin and has been stubborn with different chemical thinning agents. In this study we evaluate the effectiveness of the flower thinning effect agent (FTEA) on 'Fuji' (late maturing variety) and 'Arisu' (early maturing variety) apple qualities such as fruit weight, L/D, hardness, number of seeds, sugar content, and acidity. FTEA was sprayed at 70\% bloom only one time. The fruit set rates of FTEA-treated ones were $34.8 \%$ for 'Fuji' and $19.9 \%$ for 'Arisu', while those of the control were $73.0 \%$ for 'Fuji' and $79.9 \%$ for 'Arisu'. Thus, the fruit set rates were $38.2-$ $60.0 \%$ lower in FTEA-treated plot than the controls. The weight of the fruits also increased by $4.6-13.0 \%$. However, there were no differences in acidity, coloring, seed number, russet and physiological disorders between the two groups. In addition, we noticed a significant increase in yield without any negative effects, and the results generally showed that FTEA has a significant effect on 'Fuji' and 'Arisu' apple fruits. For the stimulation effect of pollen tube elongation, the results indicated no effect of FTEA on pollen tube elongation in an in vitro experiment. FTEA treatment significantly reduced total cost and labor force of flower thinning activity in apple orchard as decreased $67.8 \%$ and $76.6 \%$. These results showed that the effects of FTEA spray for flower thinning were significant for both 'Fuji' and 'Arisu' varieties for fruit weight, thinning cost, and labor force reduction.
\end{abstract}

Key words: apple, chemical thinning, flower thinning, fruit set, labor force reduction

\section{INTRODUCTION}

Thinning apple fruitlets by hand is often impossible because of labor costs and the limited supply of available labor (Stopar 2006). Therefore, the development of chemical thinning is needed to ensure profitable apple production.

During the reproductive process, many types of fruits trees produce more fruit than they can support to maturity, and as a consequence this affects fruit quality such as size, weight and production in general. To avoid this biennial production, many researchers have been searching for an effective thinning method. In the beginning, hand thinning was the only method to reduce the number of fruits. However, this method presents time limitations due to weather, high labor costs, and skilled labor in thinning. Therefore, this method is neither economical nor practical. All these reasons have stimulated interest in chemical thinning (Xiao et al., 2014; Dias et al., 2018).

Chemical thinning in apple cultivation uses ethephon, ammonium thiosulphate, napthylacetic acid, car-

\footnotetext{
Department of Farm Management, College of Agriculture and Life Sciences, Kyungpook National University, 80, Daehak-ro, Buk-gu, Daegu, 41566, Republic of Korea

2 School of Applied Biosciences, College of Agriculture and Life Sciences, Kyungpook National University, 80, Daehak-ro, Bukgu, Daegu, 41566, Republic of Korea

Institute of Agricultural Science and Technology, Kyungpook National University, 80, Daehak ro, Buk-gu, Daegu, 41566, Republic of Korea

* Corresponding author (E-mail: leeky@knu.ac.kr)
}

baryl, benzyladenine, ethephon, conjugates of naphthalene acetic acid and NAA, and gibberellins (Jones et al., 1983; Greene, 1989; Nielsen and Dennis, 1993; Jemric et al., 2003; Matta and Ouma 2007; Berlanga Reyes 2008). Many thinning agents such as NAA, ethephon, and 6-BA have been applied to 'Fuji' apples (Guak et al., 2002). Naphthaleneacetamide (NAD) has also long been in use. It acts as a synthetic auxin. NAD should be applied from the peak of the blossoming period to up to one week after the end of the blossoming period. NAD is considered to be a weak thinning agent (Westwood, 1993; Stopar 2006). NAD cannot be used on 'Delicious' trees because it induces the formation of a large number of pygmy fruit that stay on the tree until harvest time (Wertheim, 2000).

Benzyladenine (BA) thinning agent was found to be good. Besides thinning, it also accelerates cell division. Apples from trees thinned with BA are therefore larger than would be expected on the basis of the thinning effect alone (Greene, 1993; Wismer et al., 1995). When used to thin 'Fuji' trees, BA is most effective when applied when the fruitlets are $10 \mathrm{~mm}$ in diameter. BA also improves return bloom (Robinson et al., 1998; Sally et al., 1991).

In case of ethephon, which has also been used for a long time, and one of its positive effects is that it improves return blooms, and it can also be applied over a longer period. However, the thinning effect of ethephon can vary considerably depending on the temperature (Olien and Bukovac, 1982). Ethephon gives inconsistent results and can even cause overthinning (Wertheim, 2000). For these reasons, it is not approved for use in 
many countries (Link, 1986). The timing of application of chemical thinners can be affected by many factors including species or cultivars and generally the time to apply fruit thinner is generally determined either by fruit size or days after bloom (Batjer et al., 1968; Donohoe, 1968; Leytry, 1973; knight and Spenser, 1987). Carbaryl is a highly toxic carbamate pesticide and its use has been reduced due to its harmful effects on pollinating insects (Dennis, 2000).

Therefore, it is necessary to develop eco-friendly thinning agents that are safe for pollinating insects as well as the environment. Some were found to be effective and some had a negative effect. Chemical thinning practices give quite unpredictable results. Nevertheless, many apple farmers want them and there are many variables to use them. Apple growers in different regions need different chemical fruit thinning responses for thinning trees with different ages, culture conditions, rootstocks, climates, and amounts of fruit desired to be removed (Byers and Carbough, 1991). Recently, an ecofriendly thinning agent, Koduri (brand name), was developed by using various organic compounds and microelements, and its safety on honeybees was demonstrated (Jahan et al., 2014). We hypothesized that flower thinning effects can be influenced by the presence and quantity of various microelements in the formulation. The objective of this research was to identify thinning effectiveness, and fruit quality by spraying flower thinning effect agents and to determine their impact on pollen tube elongation and the degree of cost reduction due to reducing fruit sets in 'Fuji' and 'Arisu' apple.

\section{MATERIALS AND METHODS}

\section{Area description}

The trial was conducted in Hwanggan, Chungpook Province of South Korea (latitude: $36^{\circ} 15{ }^{\prime} 54.08^{\prime \prime}$, longitude: $127^{\circ} 55^{\prime} 04.42^{\prime \prime}$ elevation: $221 \mathrm{~m}$ ) in 2019.

\section{Plant materials}

The apple variety used is 'Fuji' (late maturing variety) and 'Arisu' (early maturing variety) developed by the Rural Development Administration of Korea. M9 rootstock, 6-year-old 'Fuji' and 'Arisu' trees of uniform size and vigor were selected to field test the flower thinning as well as fruit quality of treatments. The planting distance was $4.0 * 1.5$ and the vitality of tree was medium. All treatment trees were subjected to the standard orchard management practices as applied at apple cultivation.

\section{Treatments applied}

The total number of blooms on each tree was counted during the middle of April 2019 before spraying the treatments. The average number of flower clusters per tree at that time was more than 100. The flower thinning effect agent (FTEA, Koduri), containing various organic compounds and microelements were sprayed just once during 50 70\% bloom. The dilution of the concentration in water was $0.1 \%(\mathrm{v}: \mathrm{v})$ and sprayed on the whole tree as 2.5 ton/ha. To prevent biased results, the treatments were arranged in a randomized complete block design replicated three times with 15 trees per replication (Table 1).

\section{Preparation of flower thinning effect agent (FTEA)}

The flower thinning effect agent (FTEA) (Apple Bio Co. Ltd., Daegu, Korea) were prepared. The FTEA were registered as a micro-element complex fertilizer, and the guaranteed ingredients were $0.7 \%$ zinc and $2 \%$ boron of water solubility. Other ingredients included seaweed extract, mannitol, nitrogen, and so on.

\section{Fruit Quality}

All the fruits were harvested on November 5, and average fruit weight was measured. A random sample of 15 apples per tree from five trees for each treatment were assessed in detail for fruit quality, including number of seed, L/D, sugar content, acidity, and firmness. All harvested fruits were measured as followed by Bhusal et al. (2016) and Matsumoto et al. (2017). Russeting and Physiological disorders were investigated every two weeks until harvesting by visual evaluation.

\section{Pollen tube elongation}

The plants of apple trees were grown in the experimental orchard described above. The flowers for experiments were collected at about 9 A.M., before the dehiscence of anthers occurred and their pollen was immediately obtained for further use. The experiments were carried out in laboratory. $1 / 1000 \mathrm{ml}$ of diluted FTEA solution was added to the MS culture medium (Murashige and Skoog 1962). Incubation was done in the sterilized, non-corrosive cavity dishes. After 60 min of incubation, the germination of pollen was measured.

\section{RESULTS AND DISCUSSION}

Table 2 shows the total thinning cost and labor force for flower thinning. The total cost of the control, lime sulfur and FTEA were 4,652.8, 3,158.9 and 1,499.6 (US\$/ ha), respectively, and decreased $67.8 \%$ with FTEA treat-

Table 1. Experiment details

\begin{tabular}{cccccc}
\hline Variety & $\begin{array}{c}\text { Plot } \\
\text { repetition }\end{array}$ & $\begin{array}{c}\text { Number of } \\
\text { trees per plot }\end{array}$ & $\begin{array}{c}\text { Total number } \\
\text { of trees tested }\end{array}$ & $\begin{array}{c}\text { Area required per plot } \\
\left(\mathrm{m}^{2}\right)\end{array}$ & $\begin{array}{c}\text { Total area } \\
\left(\mathrm{m}^{2}\right)\end{array}$ \\
\hline Fuji (M9) & 3 & 15 & 45 & $270.0+90$ (non-treated) & 720 \\
Arisu (M9) & 3 & 15 & 45 & $270.0+90$ (non-treated) & \\
\hline
\end{tabular}


Table 2. Effect of saving thinning cost and labor force expenses for 'Fuji' apple cultivation

\begin{tabular}{|c|c|c|c|c|c|}
\hline & $\begin{array}{c}\text { Price of } \\
\text { thinning agent } \\
(\$ / \text { ha })\end{array}$ & $\begin{array}{l}\text { Hand thinning } \\
\text { labor force } \\
\text { (people/ha) }\end{array}$ & $\begin{array}{l}\text { Hand thinning } \\
\text { expenses }{ }^{\mathrm{x}} \\
\text { (\$/ha) }\end{array}$ & $\begin{array}{l}\text { Total cost }{ }^{w} \\
(\$ / h a)\end{array}$ & $\begin{array}{c}\text { Saving Rates } \\
(\%)\end{array}$ \\
\hline Control & 0.0 & 64.0 & $4,652.8$ & $4,652.8$ & 0.0 \\
\hline Lime sulfur (two times) & 250.9 & 40.0 & $2,908.0$ & $3,158.9$ & 32.1 \\
\hline FTEA & 409.1 & 15.0 & $1,090.5$ & $1,499.6$ & 67.8 \\
\hline
\end{tabular}

${ }^{z}$ Based on recommended amount per unit area, ${ }^{y}$ Convert to base 8 hours/day, ${ }^{\mathrm{x}}$ Labor cost $\$ 72.7 /$ person/day, ${ }^{\mathrm{w}}$ Price of thinning agent + Hand thinning labor force, ${ }^{v}$ Total cost (control-treat) / Total cost (control) $\times 100$.

ment. The labor force needed for the control, lime sulfur and FTEA were 64, 40 and 15 person/ha, and decreased $76.6 \%$ with FTEA treatment. Therefore, FTEA treatment significantly reduced the total cost and labor force for flower thinning activity in the apple orchard.

Fruit set rates in 'Fuji' and 'Arisu' varieties were compared between the untreated control and FTEAtreated plots (Table 3). In 'Fuji' variety, the fruit set rate of FTEA-treated one was $34.8 \%$ with $33.0 \%$ of terminal flowers and $36.6 \%$ of axillary flowers, while that of the control was $73.0 \%$ with $77.7 \%$ of terminal flowers and $68.3 \%$ of axillary flowers. Thus, the fruit set rate was $38.2 \%$ higher in untreated plot. In 'Arisu' variety, the fruit set rate of FTEA-treated one was 19.9\% with $18.8 \%$ of terminal flowers and $21.0 \%$ of axillary flowers, while that of the control was $79.9 \%$ with $82.9 \%$ of terminal flowers and $76.9 \%$ of axillary flowers. Thus, the fruit set rate was $60.0 \%$ higher in the untreated plot. These results showed that the effect of FTEA spray was significant for both 'Fuji' and 'Arisu' varieties.

The apple fruit quality of 'Fuji' and 'Arisu' varieties were compared between the untreated control and
FTEA-treated plots (Table 4). For the 'Fuji' variety, the weights of the control and FTEA-treated fruit were $310.6 \mathrm{~g}$ and $351.0 \mathrm{~g}$, respectively, and was $11.3 \%$ higher for the FTEA-treated fruit. L/D, hardness, and sugar content of the control and FTEA-treated apples were 0.84 and $0.89,1.33$ and 1.36 , and 13.8 and 14.2 , respectively. However, there were no differences in acidity, coloring, seed number, russeting and physiological disorders between the two groups. The 'Fiji' variety did not show any symptoms of physiological disorders, russeting or morphological changes, while the 'Arisu' variety showed slight russet symptoms, but this was observed in both groups, which indicated that this was not an effect of FTEA treatment. These are similar to results by Byers et al. (1991) who reported that shading reduced viable seed numbers by about 50\% for 'Golden Delicious' apples in fruit remaining at harvest, but chemical thinning agents did not affect viable seed number and increased fruit size (Stopar 2006). Manual and chemical thinning of blossoms or fruits to enhance fruit size are practiced for a number of fruit crops (Kon et al., 2018).

Figure 1 showed the results of an in vitro experi-

Table 3. Fruit set rate after the application of FTEA to 'Fuji' and 'Arisu' apples

\begin{tabular}{cccc}
\hline & & Fruit set rate (\%) & \\
\cline { 2 - 4 } Variety & Terminal flower & Axillary flower & $\begin{array}{c}\text { Terminal flower }+ \\
\text { Axillary flower }\end{array}$ \\
\cline { 3 - 4 } Fuji & $33.0 \pm 3.8$ & $36.6 \pm 3.7$ & 34.8 \\
Control (Fuji) & $77.7 \pm 2.9$ & $68.3 \pm 3.2$ & 73.0 \\
Arisu & $18.8 \pm 3.6$ & $21.0 \pm 4.1$ & 19.9 \\
Control (Arisu) & $82.9 \pm 2.8$ & $76.9 \pm 3.0$ & 79.9 \\
\hline
\end{tabular}

Table 4. Fruit quality by treatment of 'Fuji' and 'Arisu' apples with FTEA

\begin{tabular}{|c|c|c|c|c|c|c|c|c|c|c|c|}
\hline Variety & $\begin{array}{l}\text { Weight } \\
\text { (g) }\end{array}$ & $\begin{array}{l}\text { Length } \\
\text { (mm) }\end{array}$ & $\begin{array}{l}\text { Diameter } \\
\text { (mm) }\end{array}$ & $\mathrm{L} / \mathrm{D}$ & $\begin{array}{l}\text { Hardness } \\
(\mathrm{kg} \cdot 3 \mathrm{~mm})\end{array}$ & $\begin{array}{c}\text { Sugar } \\
\text { content } \\
\left({ }^{\circ} \mathrm{BX}\right)\end{array}$ & $\begin{array}{c}\text { Acidity } \\
(\%)\end{array}$ & $\begin{array}{l}\text { Coloring } \\
(0 \sim 9)\end{array}$ & $\begin{array}{c}\text { Number } \\
\text { of seeds } \\
\text { (ea) }\end{array}$ & Russet $^{z}$ & $\begin{array}{c}\text { Physiological } \\
\text { disorder }\end{array}$ \\
\hline Fuji & $351.0 \pm 9.0$ & 80.4 & 90.3 & $0.89 \pm 0.01$ & $1.36 \pm 0.10$ & $14.2 \pm 0.5$ & $0.36 \pm 0.03$ & 6.5 & $9.2 \pm 0.1$ & 0 & 0 \\
\hline $\begin{array}{l}\text { Control } \\
\text { (Fuji) }\end{array}$ & $310.6 \pm 8.3$ & 74.0 & 88.0 & $0.84 \pm 0.01$ & $1.33 \pm 0.15$ & $13.8 \pm 0.8$ & $0.37 \pm 0.04$ & 6.5 & $9.0 \pm 0.2$ & 0 & 0 \\
\hline Arisu & $285.8 \pm 7.4$ & 75.5 & 82.8 & $0.95 \pm 0.07$ & $1.17 \pm 0.10$ & $14.1 \pm 0.4$ & $0.33 \pm 0.02$ & 8.0 & $9.1 \pm 0.2$ & 2 & 0 \\
\hline $\begin{array}{l}\text { Control } \\
\text { (Arisu) }\end{array}$ & $273.3 \pm 7.3$ & 73.3 & 76.7 & $0.91 \pm 0.08$ & $1.19 \pm 0.07$ & $14.0 \pm 0.4$ & $0.33 \pm 0.01$ & 8.0 & $9.1 \pm 0.3$ & 2 & 0 \\
\hline
\end{tabular}

\footnotetext{
${ }^{z}$ Visual evaluation 0: no physiological disorder, 9: severe physiological disorder.
} 
ment on the stimulation effect of pollen tube elongation when of FTEA was added to pollen culture medium. The rates of pollen tube elongation of untreated, 500and 1000-times dilutions were observed under a microscope $1 \mathrm{~h}$ after treatment. Their germination rates were about $83 \%$ in all three groups. This result indicated no effect of FTEA on pollen tube elongation. Therefore, FTEA is an eco-friendly flower thinning agent without any effects on apple fruition. In the other flower thinning, Liquid lime sulfur + stylet-oil and ammonium thiosulfate (ATS) reduced the number of pollen tubes that entered the style for 'Golden Delicious' by $75 \%$ and $63 \%$, respectively. Endothall and naphthaleneacetamide (NAD) did not affect the number of pollen tubes that entered the style (Kon et al., 2018).

Figure 2 shows the weather conditions before and after when FTEA was treated in April May 2019. FTEA was treated one time into 'Fuji' and 'Arisu' varieties on April 27, which showed mean temperature $10.5^{\circ} \mathrm{C}$ with minimum $3.9^{\circ} \mathrm{C}$ and $\max 16.8^{\circ} \mathrm{C}$. In general, 'Arisu' variety bloom faster a few days than 'Fuji'. But 2019 was similar. Fruit set rate was determined on May 15, which was 18 days after spraying. There were some rains on April 23, 24, 26 and 29, but no significant effect on FTEA activity was assumed.

\section{CONCLUSION}

The major labor force required for apple cultivation is for flower thinning, pruning, management of pests, diseases, and weeds, and harvesting. Among them, thinning and harvesting require the biggest labor force. The season for apple thinning is busy and requires intensive labor in many other agricultural fields. Therefore, it is necessary to reduce labor force requirements by developing labor-saving types of mechanized thinning techniques. Although many studies have been conducted on developing such techniques, farmers in the field have not been very satisfied with them. This study showed the development possibilities of a flower thinning product that can save labor in agricultural fields and is beneficial for the efficient use of labor forces in the active
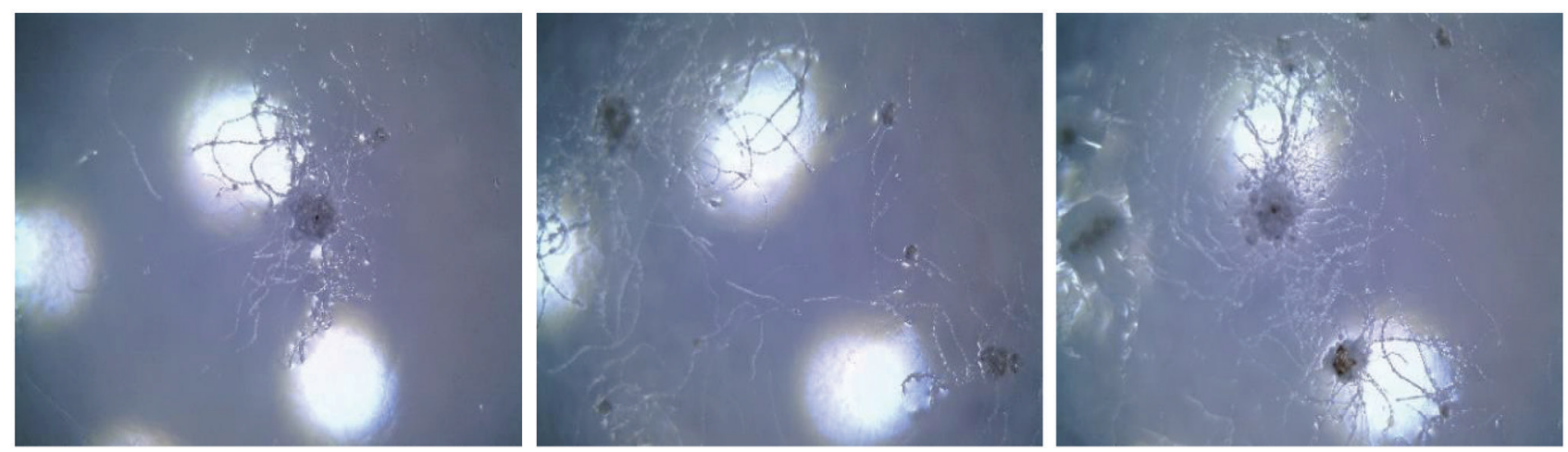

Fig. 1. In vitro investigation of pollen tube elongation by FTEA treated. (left: control; middle: thinning agent contained (500 X); right: thinning agent $(1,000 \mathrm{X}))$.

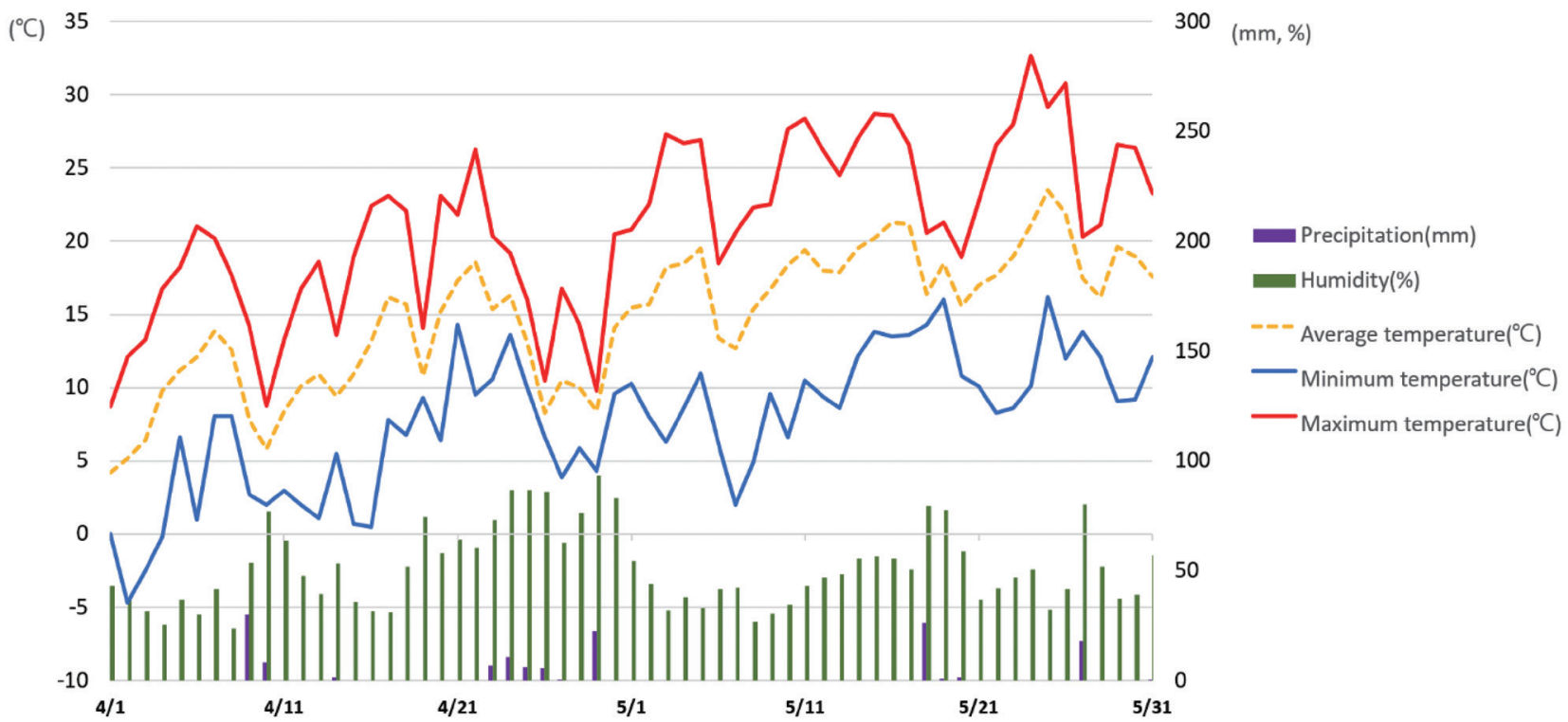

Fig. 2. Weather conditions. Full blooming: May 01, Application date: April 27. 
season. In addition, the use of flower thinning products has a positive effect on the prevention of biennial fruiting phenomenon and high-quality apple production. This study showed that this flower thinning product is not harmful to pollinating insects in the orchards. Therefore, this is an environmentally friendly product that can contribute to the development of agriculture in the future.

The timing of application of chemical thinners can be affected by many factors including species or cultivars. Apple growers in different regions need different chemical fruit thinning responses for thinning trees of different ages, culture conditions, rootstocks, climates, and amounts of fruit desired to be removed. Blossom thinning has the greatest potential to increase fruit size (Lakso et al., 1996), and can promote return blooms in the following season (Batjer, 1965; Bobb and Blake, 1938). According to the observations of our research for many years, it seems that the return bloom is more affected in the late maturing variety than in the early maturing variety.

There was a thinning effect in two apple varieties using FTEA. Fruit from FTEA treatment had a higher weight. However, in the other parameters, L/D, hardness, number of seeds, sugar content and acidity shown no differences compared to a non-treated plot.

One of the primary difficulties in the development of flower thinning agents is the consistency that can be applied to various orchards without any variations in thinning effects. The variation in thinning effects in each orchard may depend on tree vigor. The flower thinning effect was higher in weaker trees than healthy trees. The flower thinning rate can be increased to $80 \%$, but some orchards that have a low thinning rate show a high fruit setting rate. To improve commercialization, it is important to increase the fidelity of the thinning effect in various orchards. Further development is necessary to improve the consistency of flower thinning effects in various conditions of orchards and environments.

\section{AUTHOR CONTRIBUTIONS}

Tae-Kwon Son was responsible for the study design and preparation of experimental materials and performed the experiments. Kyeong-Yeoll Lee analyzed the data and drafted the paper and Yukio Ozaki verified the data and reviewed the manuscript.

\section{ACKNOWLEDGEMENTS}

This work was supported by the Korea Institute of Planning and Evaluation for Technology in Food, Agriculture, Forestry (IPET) through the Technology Commercialization Support Program and Advanced Production Technology Development Program funded by the Ministry of Agriculture, Food and Rural Affairs
(MAFRA) (grant numbers: 817022-3 and 112044-3).

\section{REFERENCES}

Batjer, L. P. 1965 Fruit thinning with chemicals. Agr. Res. Serv. USDA Washington DC Agr. Res. Bul., No. 289

Berlanga Reyes, D. I., A. Romo Chacon, A. R. Martinez Campos and V. M. Guerrero Prieto 2008 Apple fruit chemical thinning in Chihuahua, Mexico. Rev. Fitotec. Mex., 31(3): 243-250

Bhusal, N., J. H. Kwon, S. G. Han and T. M. Yoon 2016 Applications of organic fungicides reduce photosynthesis and fruit quality of apple trees Hortic. Sci. Technol., 34(5): 708718

Bobb, A. C. and M. A. Blake 1938 Annual bearing in the 'Wealthy' apple was induced by blossom thinning. Proc. Amer. Soc. Hort. Sci., 36: 321-327

Byers, R. E. and D. H. Carbaugh 1991 Effect of chemical thinning sprays on apple Fruit Set. J. Amer Soc. Hort. Sci., 116: 41-48

Cartagena, J. R. and F. B. Matta 1994 Chemical fruit thinning of vaccinium ashei reade. J. Amer. Soc. Hort. Sci., 119(6): 11331136

Cuevas, J., J. J. Hueso and A. Martinez 2004 Chemical fruit thinning of loquat by NAAm. Plant Growth Regul., 43(2): 145-151

Dias, P. A., A. Tabb and H. Medeiros 2018 Apple flower detection using deep convolutional networks. Computers in Industry, 99: $17-28$

Greene, D. W. 1989 Regulation of fruit set in the fruits with plant growth regulators. Acta Hort., 239: 323-334

Guak, S., B. Michael and E. L. Norman 2002 Thinning 'Fuji' apple blossoms with synthetic auxins (MCPB-ethyl or NAA) and ethephon with or without post-bloom thinning with carbaryl. $J$. Amer. Soc. Hort. Sci., 127(2): 165-170

Jemric, T., N. Pavicic, D. Blaskovic, M. Krapac and D. Pavicic 2003 The effect of hand and chemical fruit thinning on 'Golden Delicious cl. B' apple fruit quality. Curr. Studies Biotech., 3: 193-198

Jones, K. M., T. B. Koen and R. J. Meredith 1983 Thinning 'Golden Delicious' apples using ethephon sprays. J. Hort. Sci., 58: $381-388$

Kon, T. M., J. R. Schupp, K. S. Yoder, L. D. Combs and M. A. Schupp 2018 Comparison of chemical blossom thinners using 'Golden Delicious' and 'Gala' pollen tube growth models as timing aids. J. Amer. Soc. Hort. Sci., 53(8): 1143-1151

Lakso, A. N., T. L. Robinson and M. C. Goffinet 1996 Influence of fruit competition on size, and the importance of early thinning. New York Fruit Qrtly, 4179

Matsumoto, K., T. Fujita, S. Sato and J. P. Chun 2017 Comparison of the effects of early and conventional defoliation on fruit growth, quality and skin color development in 'Fuji' apples. Hortic. Sci. Technol., 35(4): 410-417

Matta, F. B. and G. Ouma 2007 Apple cultivar responses to fruit thinning agents accel and carbaryl in northern Mississippi. Bulletin (MAFES), 1161: 1-9

Murashige, T. and F. Skoog 1962 A revised medium for rapid growth and bioassays with tobacco tissue cultures. Physiol. Plant., 15: 473-497

Nielsen, J. C. and F. G. Dennis 1983 Thinning 'Delicious' apples; trials and tribulations. J. Hort. Sci., 28: 484

Stopar, M. 2006 Thinning of 'Fuji' apple trees with ethephon, NAD and BA, alone and in combination. J. Fruit Ornament. Plant Res., 14: 39-45

Wertheim, S. J. 2000 Developments in the chemical thinning of apple and pear. Plant Growth Regul., 31: 85-100

Xiao, C., L. Zheng, H. Sun, Y. Zhang, and M. Li 2014 Estimation of the apple flowers based on aerial multispectral image. Amer. Soc. Agric. Biol. Engineer., 4426-4433 
